\title{
MIDIATIZAÇÃO E COMUNICAÇÃO ORGANIZACIONAL: APROXIMAÇÕES TENTATIVAS
}

\author{
Mediatization and organizational communication: tentative approaches \\ Mediatización y comunicación organizacional: aproximaciones tentativas
}

Rudimar Baldissera

Professor do Departamento de Comunicação e do Programa de Pós-Graduação em Comunicação da UFRGS rudimar.baldissera@ufrgs.br

\author{
Bruno Vinhola \\ Doutorando em Comunicação na UFRGS e bolsista CAPES \\ bruno.vinhola@gmail.com
}

\section{Resumo}

No artigo temos como objetivo explorar a interface entre os estudos de midiatização e de comunicação organizacional. Para isso, mobilizamos alguns dos constructos basilares dessas vertentes, em um exercício que põe em contato, respectivamente, as noções de circulação e cultura organizacional. Propomos como fecundas as abordagens que, ultrapassando os simples usos e apropriações das técnicas midiáticas, admitem que a midiatização tensiona e perturba as organizações, portanto a comunicação e a cultura organizacionais. Assim, a partir de tensionamentos que emergem dessa aproximação conceitual tentativa, dentre outras coisas, afirmamos que a cultura organizacional precisa assimilar de modo mais profundo as atualizações geradas pela midiatização.

Palavras-chave: Midiatização. Comunicação organizacional. Cultura Organizacional.

\begin{abstract}
In the article we aim to explore the interface between mediatization and organizational communication studies. For this, we mobilized some of the basic constructs of these strands in an exercise that put in touch, respectively, the notions of circulation and organizational culture. We propose as fertile the approaches that, surpassing the simple uses and appropriations of the media techniques, admit that the mediatization tensions and disturbs the organizations, therefore the communication and the organizational culture. Thus, from the tensions that emerge from this tentative conceptual approach, among other things, we affirm that organizational culture needs to assimilate more deeply the updates generated by mediatization.
\end{abstract} Key words: Mediatization. Organizational communication. Organizational culture.

\section{Resumen}

En el artículo pretendemos explorar la interfaz entre la mediatización y los estudios de comunicación organizacional. Para esto, movilizamos algunas de las construcciones básicas de 
estos hilos, en un ejercicio que pone en contacto, respectivamente, las nociones de circulación y cultura organizacional. Proponemos como fértiles los enfoques que, superando los simples usos y apropiaciones de las técnicas de los medios, admiten que las tensiones de mediatización perturban a las organizaciones, por lo tanto, a la comunicación y la cultura organizacional. Con esto, a partir de las tensiones que surgen de este enfoque conceptual tentativo, entre otras cosas, afirmamos que la cultura organizacional necesita asimilar más profundamente las actualizaciones generadas por la mediatización.

Palabras clave: Mediatización. Comunicación organizacional. Cultura Organizacional.

\section{ORIENTAÇÕES INTRODUTÓRIAS ${ }^{1}$}

No campo da Comunicação, os estudos que articulam comunicação organizacional e midiatização têm assumido mais relevo. Essas duas vertentes que, em princípio, apresentam significativas distinções em seus fundamentos teóricos, quando tensionadas podem se constituir em fertilidade de pesquisa. Dentre outras posturas, afloram trabalhos que partem das bases teóricas da midiatização, elegendo processos de comunicação organizacional como objetos de estudos, bem como estudos da comunicação organizacional que acionam os fundamentos da midiatização para evidenciar as afetações desse fenômeno no contexto das organizações. Nesse cenário de interfaces, as perspectivas redutoras são permanentes ameaças.

Como aproximação tentativa, neste trabalho, acionamos fundamentos basilares dessas vertentes com a intenção de evidenciarmos algumas das potencialidades para estudos que, nessa interface, relacionam as noções de circulação e cultura organizacional, em perspectiva da comunicação organizacional. Portanto, não se trata de um estudo que apresenta dados empíricos ou que se propõe a reafirmar a necessidade de as organizações saberem empregar estrategicamente as mídias. Antes, a proposta caracteriza-se por ser uma tentativa de ampliar as lentes para evidenciar a potência da aproximação dessas noções (possibilidades emergentes) para os estudos que articulam comunicação organizacional e midiatização.

\section{SOBRE ORGANIZAÇÕES E CULTURA ORGANIZACIONAL}

Em perspectiva de melhor atingirmos os objetivos deste estudo, destacamos, mesmo que de modo sucinto, alguns marcos teóricos basilares para os estudos organizacionais. Primeiro, ressaltamos que as teorias acerca das organizações, apesar da sua atual transversalidade, construíram seus alicerces no campo da Administração e somente depois foram influenciadas por outros campos de conhecimento. Nesse sentido, Motta (2003) explica que diferentes pensadores do século XIX empenharam-se em desenvolver estudos (e

\footnotetext{
${ }^{1}$ Este trabalho de pesquisa contou com apoio CNPq e CAPES.
} 
disciplinas) cunhados na ideia de que não apenas o trabalho, mas a sociedade como um todo, poderia ser organizada racionalmente. Um pouco mais tarde, já no século XX, a chamada Escola Clássica da Administração, dos pioneiros Frederick Winslow Taylor e Jules Henri Fayol, intensificou essa preocupação, direcionando estudos para a racionalização e a organização dos métodos e sistemas de trabalho. É nessa época que se consolida a metáfora da organização como máquina, sendo os operários suas engrenagens.

A partir do final da década de 1920, a corrente que fica conhecida como Teoria ou Escola das Relações Humanas, e teve George Elton Mayo como seu autor expoente, propõe que as interações dos indivíduos nas organizações deveriam receber mais atenção. Assim, o comportamento dos operários (indivíduos com necessidades e pulsões) passa a ser reconhecido como algo impossível de se reduzir a esquemas mecanicistas. Motta (2003) defende que esse foi o início da transição de uma teoria da administração para uma teoria das organizações. A essa corrente interessa o sistema social em que a administração se exerce. A psicologia (na época, em especial, o behaviorismo) ganha terreno e a organização passa a ser vista como uma rede de tomada de decisões que depende tanto de fatores estruturais quanto de comportamentais.

Gradualmente, o conhecimento produzido em outros campos se faz presente nos estudos organizacionais. Na década de 1960, conforme explica Motta (2003), princípios do funcionalismo e do estruturalismo, tais como a sociedade entendida como sistema em mudança contínua, o conflito entre grupos como processo social básico, e o bem-estar social dependente do resultado desses conflitos, tensionam as concepções que nortearam as organizações na primeira metade do século. A racionalidade do sistema, perturbada pela imprevisibilidade, começa a ser questionada. Nesse contexto, também fortemente pressionados pela teoria dos sistemas abertos (originária das ciências biológicas), os estudos organizacionais são solicitados a atentarem mais para as relações entre organizações e ambientes. Disso afloram discussões sobre conceitos como importação e exportação de energia, processamento, entropia, ciclo de eventos e retroalimentação e diferenciação.

$\mathrm{Na}$ esteira do pensamento sistêmico emerge a teoria contingencial, focada nas diferenças entre organizações. Essa atenção para os fatores contextuais (modelo diferenciaçãointegração) se constituiu em fertilidade para a estabilização do pressuposto de que não há uma única maneira certa de administrar, daí ser tão importante conhecer os níveis de diferenciação entre os grupos e organizações. Nesse momento, já nos anos 1970, “o ambiente organizacional é visto como o império da desordem, exigindo consideração dos membros da organização como agentes sociais complexos" (MOTTA, 2003, p. 33). Mesmo que não seja possível entrar em 
detalhes neste texto, cabe destacar que outras correntes dos estudos organizacionais também se fundamentaram em princípios da teoria dos sistemas abertos, como: o participacionismo, os estudos da cultura organizacional, as abordagens com viés da psicanálise, os estudos sobre poder, a teoria da ecologia populacional, a teoria da dependência de recursos e, até mesmo, abordagens prescritivas neoclássicas. São diferentes abordagens sob um histórico de influências que, no geral, assumem a complexidade da organização como sistema social, admitem o indivíduo que a compõe como agente complexo e reconhecem que os contextos específicos de cada organização se traduzem em diferenciação, não cabendo, portanto, reducionismos ou generalizações.

Nessa contextura de múltiplas influências, a própria noção de 'organização' exige ser complexificada. Já não basta a concepção de que organização consiste em um grupo/unidade social (um agrupamento) constituído para alcançar um fim específico. Sem rechaçar esse tipo de entendimento, Uribe (2007) afirma a necessidade de sua problematização, pois 'agrupamento' não é sinônimo de 'organização' uma vez que existem dois tipos de agrupamentos humanos: as 'simples' comunidades, que se constituem a partir de uma ordem social espontânea e informal; e as organizações, que surgem de uma ordem social criada, dirigida (endógena ou exógena). Dessa forma, o autor defende que ficam mais claras as questões em torno dos propósitos específicos e explícitos de uma organização, pois, entendidos assim, os mesmos tornam-se suscetíveis de gestão. Ainda sobre os agrupamentos, Schvarstein (2002), pelo ângulo de entrada da psicologia social, salienta que as organizações não apenas são ou incluem grupos; são mais que simples conjuntos, pois tanto os determinam quanto são determinadas por eles. Para o autor, as organizações são unidades compostas, sendo que o caráter de construção social que apresentam resulta das interações entre os sujeitos que as constituem. Portanto, para uma organização existir não basta a intenção - normas, meios e instrumentos -, também é fundamental a interação (URIBE, 2007).

À luz das reflexões desses autores, compreendemos organização como construção social realizada por sujeitos em interação, a partir de uma ordem social criada (intenção) em torno de objetivo(s) comum(ns) e que, para isso, desenvolvem regras e normas de gestão frente perturbações endógenas e exógenas. Além do(s) objetivo(s) comum(ns), nas interações que estabelecem, os sujeitos também atualizam seus objetivos particulares, tornando as organizações mais complexas. Complementarmente, destacamos que Schvarstein (2002) sustenta que os lugares organizacionais, como construções sociais, são "virtuais", tendo em vista a impossibilidade de apreensão direta de tudo o que se passa em uma organização, pois 
esse "todo" se constitui em pluralidade de significantes. Assim, a organização é compreendida, também, como conjunto estruturado de percepções. E isso remete à afirmação de Thompson (1995) de que a vida social não pode ser resumida a apenas objetos e fatos, mas expandida a ações e expressões significativas. Estamos, então, diante do caráter simbólico da organização, do ente organização como construção social. Nessa direção, para melhor compreendermos essa qualidade, importa recuperarmos - mesmo que rapidamente - a noção de cultura organizacional.

Em perspectiva essencialmente semiótica, Geertz (1989) afirma que a cultura é uma "teia de significados" que foi tecida pelo homem e à qual ele se prendeu. Primeiro, atentamos para o fato de que a metáfora da teia confere importância fundamental à ação humana, pois que a (re)tessitura da teia é processo e resultado, nunca cristalizado, de suas ações simbólicas e das relações de poder que aí se atualizam, de modo que os sujeitos tecem a cultura e são por ela tecidos. Essa "teia de significados", conforme Baldissera (2009b), exerce-se como força coercitiva-formadora sobre os/dos sujeitos que a ela se prenderam, ainda que não os determine, prescrevendo comportamentos, normatizando compreensões, impondo verdades e modelos a serem seguidos e procurando dirimir dúvidas, dentre outras coisas. Dessa forma, “[...] a cultura de um grupo, em algum nível e de alguma forma, inocula-se nos sujeitos maculando-os" (BALDISSERA, 2009b, p. 9).

Voltando nosso olhar especificamente para as organizações, e com base no pressuposto de que são construções resultantes das interações entre sujeitos, parece evidente que também são estruturas significativas, teias de significação. Nessa direção, dentre outras coisas, cabe destacarmos que ao se articularem para constituir uma organização, conforme Baldissera (2009a), os indivíduos o fazem a partir das culturas dos grupos aos quais pertencem. Sem que se trate de sobreposição total ou determinação (até porque a cultura é (re)tecida pelas interações materializadas pelos sujeitos), tais redes de significação, particularmente as que são portadas pelas lideranças, tenderão a se exercer como forças (em diferentes graus) na conformação da cultura organizacional.

De acordo com Schein (2009), qualquer interação espontânea de um grupo, com o tempo, leva a padrões e normas de comportamento que formarão a cultura de tal grupo e, em grupos formais como as organizações, é comum que um ou mais indivíduos criem esse grupo e se tornem líderes. Esses fundadores portam redes de significação dos seus grupos de origem e, voluntariamente ou não, tendem a exercê-las sobre os sujeitos com os quais interagem constituindo a organização. Nesse sentido, Schein (2009, p.15. Grifo do autor) ressalta que não se trata de simples imposição e não produz cultura em si, pois que essa relação, em princípio, 
apenas gera confiança para que os seguidores façam o que os líderes solicitam ou ordenam, de modo que "apenas se o comportamento resultante levar ao 'sucesso' [...] as crenças e valores do fundador serão confirmados e reforçados e, mais importante, passarão a ser reconhecidos como compartilhados".

Dessa forma, segundo Schein (2009), o processo de formação da cultura organizacional se inicia por esse padrão de suposições básicas compartilhadas, que é resultado de experiências aprendidas pelo grupo a partir de situações-problema. Tais suposições básicas, depois de consideradas válidas, passam a ser ensinadas aos novos membros em uma infinita tentativa de padronização, integração e formação de consenso. Para o autor, elas são os valores inegociáveis da cultura do grupo, e incluem crenças, percepções e sentimentos inconscientes assumidos como verdadeiros ${ }^{2}$.

Em sentido de não redução aos processos de integração e consenso, Martin (1992) postula que três principais dinâmicas de interação entre sujeitos tendem a conformar e a caracterizar a cultura organizacional: a da "integração", orientada pela tentativa de harmonia e homogeneidade, de modo que o consenso é muito valorizado; a da "diferenciação", que cede espaço aos conflitos de interesses entre indivíduos e grupos e aceita o consenso apenas nos limites das subculturas; e a da "fragmentação", que dá ênfase às ambiguidades, admitindo consenso e dissenso em alternância constante na multiplicidade de fluxos e incertezas. Entretanto, cabe observar que a própria autora ressalta que tais dinâmicas não são excludentes e, inclusive, qualquer contexto cultural pode ser (e geralmente é) atravessado pelas três perspectivas.

Reconhecendo a complexidade dessas dinâmicas, atualizadas em permanentes processos de (des/re)organização do (re)tecer a cultura organizacional, Baldissera (2009a) afirma que apenas parte dos sentidos movimentados e disputados pelos sujeitos em interações é selecionada (nem sempre de modo racional) pelos membros do grupo, particularmente pelos gestores (pois que têm poder de decisão), para constituir cultura. Esses sentidos selecionados, estabilizados em diferentes graus, configuram as teias de significação, e são materializados em valores, crenças, padrões, normas, rituais e comportamentos, entre outras manifestações culturais. Complementarmente, o autor destaca que à medida que a organização se estrutura portanto também conforma a cultura organizacional - pode receber outros integrantes que, por

\footnotetext{
${ }^{2}$ Conforme Shein (2009), além do nível das suposições básicas ou pressupostos (nível mais profundo), há outros dois níveis da cultura organizacional: 1) o das crenças e dos valores assumidos explicitamente (referem-se ao que foi "validado" socialmente e passa a ser orientado conscientemente, como uma espécie de guia); e 2) o dos artefatos visíveis (fenômenos materializados, tais como linguagem, arquitetura, produtos, vestuário e histórias).
} 
sua vez, podem perturbar, em diferentes intensidades (dentre outras coisas, dependendo do lugar desses sujeitos na organização e dos capitais que portam), a rede de significação que foi tecida, particularmente com a influência dos seus fundadores e/ou líderes. Assim, a cultura organizacional, continuamente (re)tecida nas mais diversas interações e experiências, também passa a ser tensionada pelas redes de significação portadas pelos novos integrantes e outros públicos, de modo que nunca poderá ser determinada de uma vez por todas pelos seus fundadores e/ou líderes.

Isso porque na metáfora do tecer o autor reconhece a cultura como algo não cristalizado, interdependente de outros sistemas, subsistemas e da interação dos sujeitos. Ela se atualiza em interações, pois os sujeitos movimentam sentidos que podem se exercer sobre ela, podendo ressignificar algum de seus aspectos. Isto é, esses sujeitos, ao compartilharem significação, ao circularem e disputarem sentidos, podem perturbar a teia de significação estabilizada em perspectiva da contínua reelaboração (tecendo, destecendo e/ou retecendo-a). Baldissera (2009a) salienta que os indivíduos, mesmo "presos" às teias de significação, recebendo prescrições e proscrições sobre o que pensar e como agir, podem (e é provável e primordial que o façam, até pela necessária atualização da cultura), em algum grau, disputar, apropriar-se, usurpar, enfim, (re)criar significação e, consequentemente, participar da constante atualização e regeneração dessas teias. Afasta-se, assim, das perspectivas esterilizantes que reduzem e condenam os sujeitos a simples reprodutores da cultura. Compreendidos como agentes portanto, não determinados -, os sujeitos são produtos e produtores da efervescência cultural. Sobre esse caráter transformador da significação, Baldissera (2008, p. 195) destaca que

a significação experimenta o permanente (re)tecer. Novas informações e experiências (de quaisquer naturezas) permitem ao sujeito reconhecer nos mesmos signos novas porções de significação e conferir a signos diferentes a mesma significação [...].

Ocorre que, em perspectiva da metáfora das teias de significação, pode-se pensar que em qualquer conformação de cultura, inclusive as organizacionais, existem nós e fios mais frouxos e outros mais resistentes nas teias de significação. Por isso, para Baldissera (2009a), é provável que os nós e fios mais frouxos (geralmente o que é periférico ou mais recente) sejam mais suscetíveis a perturbações e consequentes transformações se comparados aos nós mais apertados, aos fios mais resistentes, às tramas mais densamente estruturadas (o que é central, mais enraizado, estabelecido). A cultura organizacional é permanente tensão entre sua tendência às padronizações, à geração de estabilizações e os processos de perturbação e 
regeneração.

Assim, pode-se afirmar que não há como pensar e explicar as organizações sem o (re)conhecimento de seus fenômenos culturais. Dessa forma, complementarmente ao mundo objetivo, assume-se aqui a perspectiva simbólica como basilar para a compreensão das lógicas organizacionais, a partir da noção de cultura organizacional como teias de significação. Teias essas que, a um só tempo, como complexus (o que é tecido junto) de significação: são urdidas pelos sujeitos em interação (que a elas se prendem); estruturam hierarquias e conformam gramáticas que se exercem sobre eles como forças coercitivas-formadoras, prescrevendo modelos, verdades e valores a serem seguidos e proscrevendo as sanções; realizam-se para gerar a própria estabilização; e são perturbadas, regeneradas e/ou (re)dinamizadas pelas interações dos diferentes sujeitos, o que pode exigir o destecer e (re)tecer as teias - ressignificação -, em diferentes intensidades e níveis. Cabe observar, ainda, que nessas interações, os sujeitos também experimentam a partir da cultura de seus grupos de origem, das suas competências, dos seus repertórios e, de especial interesse para esta reflexão, em contexto de midiatização.

\section{BREVES CONSIDERAÇÕES SOBRE MIDIATIZAÇÃO E CIRCULAÇÃO}

Reconhecendo que as organizações, na condição de sistemas sociais abertos, coabitam a paisagem atravessada pelo fenômeno da midiatização, sendo por ele irritadas e influenciadas, importa destacarmos algumas questões relativas a ele. Atualmente, os estudos de destaque da midiatização podem ser agrupados em três grandes perspectivas: a corrente institucionalista (escandinava), a escola socioconstrutivista (alemã) e a tradição latino-americana (da qual nos aproximamos mais), que dá ênfase ao processo de semiose humana e concebe que as lógicas de mídia(s)/midiatização reconfiguraram a sociedade.

No contexto de pesquisa latino-americano, compreendemos a midiatização como "resultado operacional de uma dimensão nuclear de nossa espécie biológica, mais precisamente, sua capacidade de semiose" (VERÓN, 2014, p.14). Em perspectiva histórica, o autor observa que as mídias, sob os mais diversos formatos, sempre estiveram presentes na vida humana; a escrita, os códices, o livro e a imprensa, por exemplo, são invenções técnicas que ativaram progressivamente a capacidade de semiose humana. Dessa forma, para Verón (2014, p.16), a midiatização é, antes de tudo, um processo: “[...] é apenas o nome para a longa sequência histórica de fenômenos midiáticos sendo institucionalizados em sociedades humanas e suas múltiplas consequências". Mesmo sendo da qualidade do processual, ainda conforme o autor, os momentos de "adoção" de dispositivos midiáticos, como a televisão e a internet, podem ser 
chamados de "cruciais" no processo de midiatização da sociedade, sem que se conformem em determinismos tecnológicos dessas rupturas, pois que a qualquer tempo são realizadas diferentes apropriações desses dispositivos inventados e, por isso, sua institucionalização exige a compreensão histórica de longo prazo.

O "momento crucial" da contemporaneidade, de institucionalização da mediação digital, revela que a midiatização está ainda mais acelerada devido ao aumento exponencial da conversão de fenômenos técnicos em novos meios (FAUSTO NETO, 2008). Essa reconfiguração de tecnologias em outras práticas midiáticas criou condições para que qualquer ator (sujeito, organização ou grupo social) se aproprie e use as técnicas e lógicas midiáticas, bem como perturbou fortemente o paradigma comunicacional até então estabelecido para as mídias, centrado na linearidade do modelo emissor $\rightarrow$ receptor (ainda que os estudos de recepção e das mediações já tivessem conferido tons de complexidade a esse modelo). Na esfera da emissão, mídias como jornal impresso, rádio e televisão, sempre estiveram sob o "controle" de poucos. E, por longo tempo, a sociedade respeitou as leis da instrumentalidade desses meios, legitimando-os como responsáveis pelo papel da mediação e tematização pública. Segundo Rodrigues (2000), da metade do século XX até os anos 1980, deu-se o período de autonomização e consumação do chamado campo midiático, que assumia a superintendência das relações societárias, permeando e expandindo-se entre as fronteiras dos demais campos sociais.

Ocorre que, com o advento da internet e a explosão da mediação digital, o chamado campo midiático é deslocado de sua posição central, pois o acesso irrestrito às técnicas e lógicas midiáticas dissipa esse elo organizador, quebrando o controle gerencial do campo dos media. Assim, essa "passagem" da linearidade à circularidade, ao colocar as esferas da emissão e da recepção em relações mais simétricas (inclusive em constantes trocas de papeis), admite a sensação de ruptura na arquitetura comunicacional. Obviamente, ainda há modos de expressão de poder das mídias tradicionais, a partir das rearticulações que as mesmas elaboram em suas adaptações à essa ambiência, mas o fato é que o tecido social está agora atravessado pela cultura de mídia (FAUSTO NETO, 2008), no sentido de que indivíduos e organizações, de modo mais intenso, não apenas têm acesso, mas também dominam e são perturbados por técnicas e lógicas midiáticas, (re)dinamizando os processos comunicacionais de maneira bem mais acelerada. Mas, por que falamos em uma 'sensação' de ruptura? Justamente pelo fato de que, conforme Verón (2014), não apenas a comunicação midiática, mas a própria comunicação humana nunca foi um processo linear. Desde suas primeiras experiências comunicativas, o ser humano 
ressignifica seu modo de ser no mundo através da sua condição de circulação de signos. Para o autor, a midiatização da sociedade nada mais é do que a macrogeneralização dessa condição.

O conceito de circulação, dessa forma, revela-se fundamental para a reflexão acerca do fenômeno da midiatização. Fausto Neto (2010), em uma linha do tempo, afirma que, primeiro, restrita ao paradigma funcionalista, a ideia de circulação permaneceu "em repouso", tratada de forma naturalizada, pois que sob a inspiração mecânica/ferramental do ato comunicacional era reduzida a zona de passagem, de transmissão automática de mensagens. A circulação era apenas o "intervalo" entre emissão e recepção, comportando pouca complexidade (em que o ruído da mensagem era o máximo de sua representação). No momento da evolução da perspectiva de linearidade do ato comunicacional para o da abordagem que contemplava a enunciação, a circulação assumiu significativos contornos de complexidade, uma vez que a enunciação, segundo Fausto Neto (2010), carrega a dimensão discursiva que retira da emissão/produção o status de "dona" do ato comunicacional. Emissão e recepção não deixam de existir, mas se trata de algo relacional. Reconfiguradas as instâncias, a zona de passagem/transmissão transformase em "zona de indeterminação". Tal abordagem foi potencializada com a evolução dos estudos de recepção, como nos lembra Braga (2012, p. 38): “com a percepção de que os receptores são ativos, a circulação passa a ser vista como o espaço do reconhecimento e dos desvios produzidos pela apropriação". Nesse sentido, Fausto Neto (2010) ressalta que a noção de zona de indeterminação comporta desajustes e descontinuidades entre os polos de emissão e recepção; a circulação é, então, tratada como diferença entre as gramáticas dos dois polos. Ainda segundo Fausto Neto (2010), as abordagens seguintes atentaram para as tentativas de redução dessa diferença e indeterminação. Surgiram os estudos sobre os chamados contratos de leitura, que procuram remodelar essa defasagem em direção à construção de vínculos entre os polos, através de diferentes estratégias de aproximação entre o discurso emitido e sua recepção. Antes zona de passagem e de indeterminação, nesse momento a circulação é entendida como zona de articulação.

Por sua vez, no atual estágio da midiatização, conforme Fausto Neto (2010), as mudanças nos regimes sócio-técnico-discursivos substituem a lógica dos contratos pela das interfaces. A paisagem circulatória passa a ser entendida como espaço de embates de várias ordens que não apenas coloca em contato as instâncias da emissão e da recepção, mas também estimula que as mesmas troquem constantemente de papeis e se movimentem conforme suas próprias dinâmicas. Fausto Neto (2010) também afirma que a construção de sentido se dá a partir de um feixe de relações em meio aos encontros e desencontros entre fluxos transversais, 
caracterizados por essa pluralidade de lógicas.

Nesse sentido, Braga (2012) propõe pensarmos para além das instâncias da produção e da recepção, pois os sentidos circulantes ultrapassam tais esferas e seguem em um fluxo sempre adiante. Isso torna impossível a distinção de pontos de partida e de chegada. Ainda de acordo com o autor, falar em fluxo contínuo não configura uma descrição abstrata; a circulação se manifesta concretamente na forma de circuitos e é dessa forma que ocorrem as negociações de sentido entre atores e campos sociais. Tais circuitos sempre são processos tentativos de experimentação midiática, de modo que alguns se tornam mais estabelecidos, enquanto outros se rompem mais facilmente. Braga (2012) salienta que, para se relacionarem nesses tempos de midiatização acelerada, atores e campos sociais ficam obrigados a se inscreverem em circuitos não usuais, fora dos padrões esotéricos de interação de cada domínio de experiência, o que fomenta cada vez mais processos tentativos e a consequente (re)criação de circuitos.

Recorrendo mais uma vez a Fausto Neto (2010), destacamos que a circulação, atualmente, qualifica-se como central dispositivo fomentador do processo de midiatização, a partir de sua lógica de acoplamentos e, dentre suas características, estão a constante troca de papeis entre as instâncias emissora e receptora, o interesse do indivíduo/organização por uso/apropriação de várias mídias ao mesmo tempo, o fluxo sempre adiante atravessado por circuitos ainda mais diversos e experimentais, as quebras de vínculos por parte da recepção, a amplificação das condições de produção e a (co)gestão do acontecimento intermidiático.

\section{APROXIMAÇÕES TENTATIVAS}

Com base nos pressupostos que destacamos, compreendemos que as organizações também são culturas (redes de significação) e a circulação, por sua vez, é dispositivo central no processo de midiatização da sociedade. Temos, então, que a circulação de significação não apenas se exerce sobre a sociedade, gerando ambiência midiatizada, senão que também é condição para a conformação da cultura organizacional. Complementarmente, se assumirmos, com Thompson (1995), que os fenômenos culturais podem ser pensados como expressões significativas produzidas e recebidas (o que supõe circulação) e que as maneiras como as formas simbólicas circulam sofrem transformações, então, podemos afirmar que, no atual estágio do processo de midiatização, as formas simbólicas circulam segundo outros protocolos que, em regime de interfaces (intra/intercultural), dentre outras coisas, ampliaram sua potência de presença, permanência e recuperação, bem como, pela fricção, agitação e/ou irritação do simbólico que circula nos espaços fronteiriços, podem se exercer como forças nos processos de 
ressignificação cultural.

À essa luz e procurando não reduzir os estudos de interface organizações-midiatização ao viés da "cultura de mídia" absorvida nas organizações, especialmente ao uso/apropriação das técnicas midiáticas, consideramos que uma das possibilidades de sua ampliação e aprofundamento é olhar para as afetações entre midiatização e organizações sob o prisma da circulação midiática e da cultura organizacional. Nesse sentido, destacamos algumas das inquietudes que emergem dessa aproximação tentativa.

A primeira inquietude diz respeito às explicações que reduzem os processos de midiatização nas organizações aos usos e apropriações de técnicas e lógicas midiáticas, geralmente limitados a determinadas práticas, setores e atores. Consideramos que há demasiada valoração dos processos comunicacionais planejados e das ações midiáticas mensuráveis, o que limita os estudos aos aspectos formais e auto-orientados da "organização comunicada" (BALDISSERA, 2009b), em detrimento dos demais processos. Para superar essa simplificação é preciso atentar para a complexidade das interações que aí se realizam, dentre outras coisas, tendo em conta as outras duas dimensões da comunicação organizacional, conforme Baldissera (2009b): a da "organização comunicante", em que, contemplando os processos da organização comunicada (falas autorizadas) e para além deles, assumem relevo os processos informais materializados em interações diretas dos diferentes sujeitos/públicos com a organização; e a da "organização falada", que compreende os processos comunicacionais indiretos, materializados fora dos ambientes da organização, mas que se referem a ela.

O atravessamento da cultura midiática e suas irritações nos contextos organizacionais tendem a levar ao pensamento acerca da "obrigação de comunicar das organizações", de modo geral restrito às falas autorizadas. Se repararmos a importância conferida pelas organizações aos usos e apropriações das técnicas e lógicas midiáticas, podemos afirmar que essa concepção está em avançado processo de absorção pela cultura organizacional, com inclinação a ser assimilada como sendo da sua natureza (própria, inerente). Entretanto, ao qualificarmos nossas lentes e analisarmos as lógicas de circulação, podemos perceber que, por exemplo, o excesso de informações produzidas e veiculadas pelas organizações combinado com a pouca escuta, podem restringir a comunicação a processos informativos para fazer-fazer (tarefismo).

Em perspectiva complementar também tendem a configurar simples práticas para as organizações dizerem de si com o desejo de estarem presentes no espaço midiático, muitas vezes até de modo indiscriminado. Nesse sentido, cabe observarmos que o processo que naturaliza a cultura de mídia traz a reboque a necessidade exponencial de aparecer, de exibir- 
se em público, isto é, a busca incessante por visibilidade. Porém, na sociedade aceleradamente midiatizada, a invisibilidade ou, pelo menos, a redução dos níveis de visibilidade pública, também é valor sob as lógicas de circulação, pois nem todas as organizações realmente querem e/ou devem ascender a esses amplos graus de visibilidade (SILVA, 2018). Assim, para além dos simples empregos das mídias e de suas gramáticas para as organizações estarem visíveis, dentre outras coisas e a um só tempo, importam as estratégias de gestão dos seus níveis de visibilidade ou opacidade de modo a se fazerem presentes na arena midiática e dizerem de si (circulem sentidos sobre si) para construírem as imagens-conceito desejadas (BALDISSERA, 2008), serem reconhecidas e (re)afirmarem sua legitimidade, bem como, em perspectiva da cultura organizacional, para implementarem políticas de comunicação que considerem o contexto de midiatização sem ser por ele determinadas.

Nesse contexto, a potência está com as organizações que não "apenas" fazem uso/apropriação de técnicas midiáticas, mas que, compreendendo as lógicas da circulação, realizam movimentos de adaptação e de assimilação à essa/dessa ambiência. Como exemplos destacamos as estratégias e táticas de Search Engine Optimization (SEO), de segmentação comportamental e de monitoramento de públicos, que revelam políticas apuradas de uso de dados por parte das organizações. Entretanto, apesar de não ser o foco deste texto, cabe ressaltarmos que não raras vezes essas estratégias e táticas põem em suspeição questões de cunho ético. Dito isso, destacamos que a coexistência com a potencialidade de dados que a circulação midiática oferece não se trata de uma escolha, e os diferentes públicos, por sua vez, se exercem cada vez mais sobre a realidade organizacional. Experimentamos a potencialização exponencial da dimensão da organização falada (BALDISSERA, 2009b), e isso exige muito mais escuta dos públicos e parcimônia no "dizer".

Como segunda questão, focalizamos o potencial das diferentes organizações para criarem dispositivos e circuitos midiáticos e as relações de poder que decorrem disso. Castells (2010) defende que a sociedade em rede reforça fontes de poder cada vez mais supra e transnacionais, a partir da reconfiguração no modo como é exercido o poder. As redes, que para o autor, são complexas estruturas de comunicação com atribuições de valor próprias, operam segundo uma lógica binária de inclusão/exclusão. A partir disso, os modos concretos em que o poder se realiza têm a ver, por exemplo, com o "poder de conectar em rede" (dos incluídos sobre os não conectados), com o "poder da rede" (quem dita as regras para estar em uma rede) ou com o "poder para criar redes" (capacidade de programação e de conexão entre diferentes redes). Admitindo essas formas de poder nas redes, explicitadas por Castells (2010), apresenta- 
se falsa a simetria na relação entre uma organização como o Facebook, dona de uma "rede social privada" repleta de normas a seguir, e as organizações que nela inscrevem seus dados e discursos. Também aqui é preciso sinalizarmos o fato de que possíveis dilemas éticos informacionais podem emergir dessa relação entre uma organização que fornece seus dados sem restrição e aquela que recebe e usa como desejar esses mesmos dados. E, nesse sentido, pode-se refletir o quão vulnerável está um sujeito ou organização inscrito em um dispositivo midiático endossado por grandes atores globais, ao passo que estão, em sua maioria, ainda distantes da possibilidade técnica de elaboração de mídias e circuitos próprios, a fim de proteger seus dados e relações.

Como terceiro aspecto, consideramos a tensão espaço físico-ciberespaço. Diante da primazia assumida pela mediação digital, como fica a comunicação organizacional face a face? É fato que se, por um lado, a ambiência midiatizada concede alto valor aos circuitos que se manifestam no ciberespaço, por outro lado, a comunicação face a face, particularmente aquela que se materializa com o público que atua nos espaços físicos das organizações (entre organização e público e/ou entre sujeitos desse público), ainda é central para grande parte delas. Portanto, é preciso admitir que a comunicação organizacional, no atual contexto e considerando as especificidades de cada organização, é conformada por processos digitais e por processos face a face; por mais que sigam lógicas diferentes, são instâncias em tensão. Um exemplo dessa relação é o fato de os consumidores já não admitirem preços diferentes entre produtos vendidos em lojas físicas e virtuais, não entenderem fluxos ágeis em um endereço eletrônico e um atendimento ruim no balcão, não suportarem adquirir um produto em uma das instâncias e não poderem resolver problemas na outra. Na comunicação organizacional materializam-se variados processos em fluxos multidirecionais, e parece ser mais fecundo pensar que a comunicação digital, dentre outras coisas, complexificou parte desses processos.

Por fim, em perspectiva intersistêmica, sob regime de tensões e acoplamentos estimulado pela circulação midiática, borram-se e confundem-se os espaços fronteiriços das especializações e misturam-se lógicas entre os diferentes domínios de saber/experiência. Se atentarmos em particular para as questões de cultura, podemos afirmar que essa ambiência amplifica as constantes trocas e as mútuas afetações de maneira que, nos circuitos midiáticos, pelos encontros de diferentes redes de significação, seja pelos movimentos organizacionais de fala autorizada e/ou pela diversidade de acionamentos informais realizados pelos sujeitos em interação, podem emergir experimentações interculturais.

Nessa ambiência de aceleração das relações interculturais, a alteridade parece estar 
sempre mais presente. Para Landowski (2002), essa facilidade contemporânea de estar em contato com a alteridade faz com que esse outro não seja mais apenas estrangeiro, marginal, dessemelhante. O outro deixa de apenas “incomodar" (não é necessariamente excluído), porque ele também é o termo que falta, sendo que os encontros com o outro contam com diferentes protocolos de negociação. Assim, conforme Landowski (2002), os movimentos políticos em relação às presenças do outro no grupo podem ser de assimilação, de exclusão, de admissão e de segregação.

Nesse contexto, é preciso que a comunicação organizacional seja pensada para sujeitos culturais multifacetados por suas identificações diversas e, ao mesmo tempo, investidos de potencial desviante ampliado. Exige também estratégias complexas de comunicação organizacional para esses encontros com as culturas dos públicos em uma paisagem intermidiática sem fronteiras bem definidas. Nesse sentido, cabe observamos que, de acordo com Henriques (2017), a noção de comunidade de interesses é uma unidade conveniente criada pelas organizações. Desse modo, por exemplo, afirma que as organizações não podem simplesmente naturalizar a chamada comunidade do entorno, aplicando unicidade onde existe grande heterogeneidade e, mais, não é possível aferir interesses dos públicos (objetivar a alteridade) sem o sério "entrar em contato". Portanto, o intercultural precisa ser pensando como pressuposto, modo de vida organizacional.

\section{CONSIDERAÇÕES}

Aqui, de maneira muito objetiva, podemos afirmar que sob vários aspectos (conforme destacamos), nossa aproximação tentativa dos conceitos de circulação e cultura organizacional revela fertilidade para os estudos de comunicação organizacional e da midiatização. Entretanto, dentre outras coisas, essa potência está em não reduzi-los a abordagens instrumentais e tarefeiras.

Para isso, importa: a) atentarmos para a complexidade da comunicação organizacional atualizada pela midiatização; b) ter como pressuposto que os diferentes sujeitos e públicos, cada vez mais, tensionam as posições e práticas organizacionais; c) compreender que a cultura organizacional exige passar por processos de (res)significação considerando a midiatização, de modo a conformar políticas de comunicação mais amplas, não reduzidas ao uso e apropriação de técnicas de mídia; d) reconhecer que as falas autorizadas (da dimensão da organização comunicada) precisam supor essa ambiência e serem materializadas com parcimônia; e) admitir que os públicos não são exterioridades e, sim, constitutivos das organizações; f) entender que 
os públicos, como virtualidade, podem se conformar a qualquer momento (não são naturais, constituem-se em relação à organização); g) perceber que mais do que obter visibilidade midiática, importa gerir os níveis e a qualidade dessa visibilidade ou de opacidade; e h) ter como premissa o fato de que a circulação e a cultura organizacional pressupõem relações de poder; dentre outras questões.

Por fim, ressaltamos que essas asserções e inquietudes, dentre outras coisas, evidenciam que para não incorrer em perspectivas redutoras de investigações que articulam os estudos de midiatização e de comunicação organizacional é necessário qualificar as lentes de pesquisa de modo a ultrapassar as análises que apenas atentam para os empregos de meios e das gramáticas das mídias.

\section{REFERÊNCIAS}

BALDISSERA, Rudimar. A teoria da complexidade e novas perspectivas para os estudos de comunicação organizacional. In: KUNSCH, Margarida M.K. Comunicação organizacional: histórico, fundamentos e processos. Volume I. São Paulo: Saraiva, 2009a.

BALDISSERA, Rudimar. Comunicação organizacional na perspectiva da complexidade. Organicom, São Paulo: USP, v.6, n.10-11, p.115-120, abril, 2009 b.

BALDISSERA, Rudimar. Significação e comunicação na construção da imagem-conceito. Revista Fronteiras: estudos midiáticos, São Leopoldo: UNISINOS, v.10, n.3, p.193-200, setembro/dezembro, 2008.

BRAGA, José Luiz. Circuito versus campos sociais. 2012. In: JANOTTI JR, Jeder; MATTOS, Maria Ângela; JACKS, Nilda (Orgs). Mediação e midiatização. Salvador: Edufba; Brasília: Compós, 2012.

CASTELLS, Manuel. Comunicación y poder. Madri: Alianza Editorial, 2010.

FAUSTO NETO, Antonio. A circulação além das bordas. In: FASUTO NETO, Antonio; VALDETARO, Sandra (Orgs). Mediatización, sociedad y sentido: diálogos entre Brasil y Argentina. Rosário: Universidade Nacional de Rosário, 2010.

FAUSTO NETO, Antonio. Fragmentos de uma analítica da midiatização. Matrizes, São Paulo: USP, v.1, n.2, p.89-105, abril, 2008.

GEERTZ, Clifford. A interpretação das culturas. Rio de Janeiro: LTZ, 1989.

HENRIQUES, Márcio Simeone. Aspectos críticos para a compreensão da lógica estratégica no relacionamento entre organizações e comunidades. Organicom, São Paulo, USP, v.14, n.26, p.32-40, janeiro/junho, 2017. 
LANDOWSKI, Eric. Presenças do outro. São Paulo: Perspectiva, 2002.

MARTIN, Joanne. Cultures in organizations: three perspectives. Oxford: Oxford University Press, 1992.

MOTTA, Fernando C. Prestes. Teoria das organizações: evolução e crítica. São Paulo: Pioneira Thompson Learning, 2001.

RODRIGUES, Adriano Duarte. Experiência, modernidade e campo dos media. In: SANTANA, R.N. Monteiro (Org). Reflexões sobre o mundo contemporâneo. Rio de Janeiro: Revan, 2000.

SCHEIN, Edgar Henry. Cultura organizacional e liderança. São Paulo: Atlas, 2009.

SCHVARSTEIN, Leonardo. Psicología social de las organizaciones: nuevos aportes. Buenos Aires: Paidós, 2002.

SILVA, Diego Wander. Comunicação organizacional e as estratégias de invisibilidade e de redução/direcionamento da visibilidade nas mídias sociais. Tese (Doutorado em Comunicação e Informação) - PPGCOM, UFRGS, Porto Alegre, 2018.

THOMPSON, John B. Ideologia e cultura moderna. Rio de Janeiro: VOZES, 1995.

URIBE, Pablo Múnera. La idea de organización: una concepción amplia para una acción efectiva. Medelín: Comunicación, 2007.

VERÓN, Eliseo. Teoria da midiatização: uma perspectiva semioantropológica e algumas de suas consequências. Matrizes, São Paulo: USP, v.8, n.1, p.13-19, janeiro/junho, 2014. 


\section{Rudimar Baldissera}

Professor e pesquisador do Departamento de Comunicação da Faculdade de Biblioteconomia e Comunicação e do Programa de Pós-Graduação em Comunicação da Universidade Federal do Rio Grande do Sul (UFRGS). Doutor em Comunicação Social. Bolsista produtividade do CNPq. Líder do

Grupo de Pesquisa em Comunicação Organizacional, Cultura e Relações de Poder (GCCOP) da

UFRGS - https://www.ufrgs.br/gccop/.

Bruno Vinhola

Doutorando em Comunicação pela Universidade Federal do Rio Grande do Sul (UFRGS) e bolsista CAPES. Mestre em Ciências da Comunicação pela Universidade do Vale do Rio dos Sinos (UNISINOS). Membro do Grupo de Pesquisa em Comunicação Organizacional, Cultura e Relações de Poder (GCCOP) da UFRGS.

\section{@ $\odot \odot \odot$}

Esta obra está licenciada com uma Licença

Creative Commons Atribuição-NãoComercial-CompartilhaIgual 4.0 Internacional 